\title{
EL REFERÉNDUM CONSULTIVO EN ESPAÑA: REFLEXIONES CRÍTICAS Y ALGUNAS PROPUESTAS DE FUTURO
}

\author{
Paloma Requejo Rodríguez
}

\begin{abstract}
SUMARIO: 1. UNA REFERENCIA AL PASADO PARA COMPRENDER EL PRESENTE. 2. LA VIGENTE REGULACIÓN DEL REFERÉNDUM EN EL ART. 92 CE. 3. Algunas propuestas DE REFORMA. 3.1. Sobre la necesidad de la reforma. 3.2. Algunas propuestas sobre la mesa. 3.3. Otras propuestas de lege ferenda. 4. BIBLIOGRAFÍA.
\end{abstract}

\section{UNA REFERENCIA AL PASADO PARA COMPRENDER EL PRESENTE}

Más allá de los antecedentes históricos que tradicionalmente suelen acompañar al estudio de cualquier institución, en este caso resulta imprescindible realizar aunque sea un mínimo recordatorio del pasado para comprender la actual regulación del referéndum en el ordenamiento español.

Teniendo en cuenta las enormes diferencias que los separan, no tiene a nuestro juicio demasiado sentido remontarse a las asambleas de la Grecia clásica, cuna de la democracia directa, en las que esclavos, metecos y mujeres quedaban al margen de la toma de decisiones, a las prácticas plebiscitarias de la República romana o a los parlamentos medievales, en los que representantes sujetos a mandato imperativo necesitaban que sus representados ratificaran las decisiones adoptadas sin contar con instrucciones previas. Estas últimas, las llamadas decisiones ad referendum, todo lo más pueden ser el origen del término objeto de este estudio.

El punto de arranque conceptual debe buscarse en la Revolución francesa. La incompatibilidad radical entre la democracia representativa, defendida por Sieyès y Montesquieu, que conforme al pensamiento liberal restringía la participación a la elección, y la democracia directa, preconizada por Rous- 
seau, que extendía aquella más allá de ese momento como signo de autodeterminación, parece superarse con la aportación de Condorcet en sus Lettres d'un bourgeois de New-Haven à un citoyen de Virginie y su influencia en el Proyecto de Constitución francesa de 1793 que por vez primera incorpora el principio referendario. Sin embargo, la amplitud de la unidad política, la complejidad de la sociedad, la necesaria rapidez y el deseo de monopolizar la toma de decisiones, junto a la desconfianza que despertaba una ciudadanía «malformada»e «influenciable» incapaz de asegurar la racionalidad de las mismas, hizo que, con la excepción de Suiza, el estado liberal decimonónico se decantara por el modelo representativo. Sólo en los últimos años del siglo diecinueve se empezaron a ver los instrumentos de participación directa como un complemento que podía corregir las deficiencias observadas en el sistema parlamentario y asegurar su pervivencia, terminando por plasmarse ya en el siglo veinte, entre otras, en la Constitución de Weimar de 1919 y en la Constitución española de 1931. Después de la Segunda Guerra Mundial se acudió al referéndum para legitimar los nuevos regímenes constitucionales, pero tras esos primeros años de cierto apogeo decayó considerablemente el recurso al mismo, al ser visto como un instrumento simplista, poco pluralista, conservador y fácilmente manipulable. Salvo en Suiza y en la Francia del General De Gaulle, en la que, recordando las prácticas napoleónicas, el referéndum fue utilizado para fortalecer al Jefe de Estado y a sus políticas eludiendo al Parlamento, habrá que esperar a la década de los setenta del pasado siglo para verlo resurgir en Italia y en España.

En España, sin olvidar los precedentes del Art. 69 del Real Decreto de 25 de noviembre de 1897 regulador de la autonomía de Cuba y Puerto Rico y de los Arts. 219 y siguientes del Estatuto municipal de 8 de marzo de 1924 nunca puestos en práctica, la implantación del referéndum a nivel constitucional, como quedó dicho, no tuvo lugar hasta 1931 en la Constitución de la II República. En un intento de potenciar el parlamentarismo racionalizado, se incorporaron, no sin polémica, distintos mecanismos de participación directa, como los plebiscitos territoriales de aprobación estatutaria del Art. 12, la iniciativa legislativa popular o el referéndum facultativo del Art. 66. Se trataba de un referéndum de naturaleza legislativa a través del cual el Pueblo, si lo solicitaba el quince por ciento del Cuerpo electoral, podía «atraer a su decisión» leyes votadas por las Cortes que no fueran complementarias de la Constitución, leyes de ratificación de convenios internacionales inscritos en la Sociedad de Naciones, Estatutos regionales o leyes tributarias, sin que el procedimiento concreto y las garantías del referéndum llegaran a ser desarrollados por la ley especial que preveía el precepto. Durante el Franquismo las consultas populares se regularon en la Ley de referéndum nacional de 1945, exigiéndose a posteriori referéndum en la reforma de cualquiera de sus Leyes fundamentales; de los que llegaron a celebrarse, el de 1947, para aprobar la Ley de sucesión, y el de 1966, sobre la Ley orgánica del Estado, buscaban la 
legitimación del régimen, convirtiéndose en plebiscitos personalistas, mientras que el referéndum sobre la Ley para la reforma política de 1976 también pretendió legitimar el régimen por venir, sentando bases democráticas, sin romper procedimentalmente con la legalidad anterior.

Con estos antecedentes y sin olvidar una experiencia comparada poco satisfactoria, recordemos los aludidos plebiscitos franceses y la tensión política que introdujo la implantación del referéndum abrogativo en Italia, no es extraño que los constituyentes españoles miraran con suspicacias la figura del referéndum. Ello llevó, como veremos a continuación, a recortar considerablemente la regulación que sobre el mismo efectuaban las primeras redacciones del texto constitucional de 1978. Junto a los referéndums que incidían en la reforma constitucional y en el modelo de organización territorial, en el Art. 85 del Anteproyecto de Constitución se contemplaban referéndums facultativos y vinculantes sobre decisiones políticas de especial trascendencia, sobre la aprobación de leyes votadas por las Cortes Generales aún no sancionadas y sobre la derogación de otras leyes ya en vigor. Si en los dos primeros casos la convocatoria correspondía al Rey a propuesta del Gobierno, a iniciativa de cualquiera de las Cámaras o de tres Asambleas autonómicas, en el último la iniciativa también podía proceder de setecientos cincuenta mil electores, remitiendo a una ley orgánica la concreción de las condiciones de las consultas, así como de la iniciativa popular vinculada tanto al impulso del referéndum como al procedimiento legislativo. Posiblemente la influencia italiana tuvo mucho que ver con la inclusión de referéndums legislativos y con la apertura de la iniciativa a la ciudadanía en el referéndum abrogativo, descartada en los dos otros casos por razones diversas, como impedir su influencia en el indirizzo político del Gobierno o evitar que pusiera de manifiesto la desconexión representantes-representados. Paradójicamente, desde la perspectiva actual, el único defensor del precepto en la redacción descrita fue Manuel Fraga Iribarne, quien invocó la función de «contrapeso a la partitocracia» que podría llegar a jugar el referéndum, frente al rechazo manifestado por el resto de fuerzas políticas, abanderadas por Jordi Solé Tura, que basaban su posición de restringir al máximo este tipo de consulta en la experiencia plebiscitaria anterior, en el temor de que resurgiera el pasado autocrático, así como en la necesidad de impulsar el sistema de partidos y de consolidar el estado democrático representativo y un parlamentarismo racionalizado ${ }^{1}$. Ello condujo a la eliminación de los referéndums legislativos de ratificación y de abrogación y de cualquier atisbo de iniciativa ciudadana en el tenor actual del Art. $92 \mathrm{CE}$ que pasamos a analizar².

${ }^{1}$ En http://www.congreso.es/consti/constitucion/elaboracion/ no sólo puede encontrarse el texto del mencionado Anteproyecto-Boletín Oficial de las Cortes, 5 de enero de 1978, n n $^{44}$-, sino el procedimiento de elaboración de la Constitución en su integridad.

${ }^{2}$ Sobre el devenir histórico del referéndum se ha consultado, GARRORENA MoRALES, Á., «Teoría y práctica española del referéndum», Anales de la Universidad de Murcia, 


\section{LA VIGENTE REGULACIÓN DEL REFERÉNDUM EN EL ART. 92 CE}

Aunque según el Art. $23 \mathrm{CE}$ «los ciudadanos tienen derecho a participar en los asuntos públicos directamente y por medio de representantes», lo cierto es que del resto de preceptos constitucionales se constata que el constituyente ha apostado por la democracia representativa y por el protagonismo de los partidos, quedando los instrumentos de participación directa reducidos a un papel secundario, complementario y excepcional, que, a nuestro entender, no satisface plenamente las expectativas generadas por el reconocimiento del derecho fundamental a la participación política en los términos señalados.

Entre las distintas consultas populares que la Constitución contempla con ese espíritu restrictivo, nos centraremos en el referéndum del Art. 92 CE. En él, el Cuerpo electoral puede ser llamado a participar en la función de dirección política, al ser interpelado sobre cuestiones políticas de especial trascendencia. Atendiendo a este concepto jurídico indeterminado a través del cual la Constitución delimita el objeto de la pregunta que luego prefigurará el Presidente del Gobierno, hay que descartar que este pueda ser una norma, sin perjuicio de que nada impida que celebrado el referéndum llegue a aprobarse para plasmar su resultado, lo que le aproxima al concepto alemán de plebiscito. Su situación en el texto constitucional, en el Capítulo II del Título III dedicado a la elaboración de las leyes, resulta, por tanto, inadecuada, ya que, una vez suprimidos los referéndums legislativos, no se ha cambiado el precepto de la ubicación en la que justificadamente aparecía en origen, pero no ya en la actualidad.

Su naturaleza, por el contrario, no deja lugar a dudas. Estamos ante un referéndum facultativo y consultivo.

Facultativo, porque nada obliga a su convocatoria, en tanto el órgano competente puede adoptar la decisión política básica que en cada caso se trate sin necesidad de que el Cuerpo electoral se pronuncie. Incluso si el referéndum llega a convocarse, la decisión realmente ya está tomada, aunque no formalizada por el Gobierno, que debe formular la pregunta de manera clara e inequívoca para que pueda constatar si el Cuerpo electoral está de acuerdo, otorgándole en ese caso el consiguiente plus de legitimidad. La

Derecho, Vol. XXXI, no 3-4, 1977, pp. 79-108; AguIAR DE LuQue, L., Democracia directa y Estado constitucional, Edersa, Madrid, 1977, pp. 3 y ss.; Linde Paniagua, E., HerreRO LERA, M., «El referéndum en la Constitución de 1978», Revista de Derecho Político, $\mathrm{n}^{\circ}$ 3, 1979, pp.17-48; Oliver Araujo, J., «El referéndum en el sistema constitucional español», Revista de Derecho Político, n 29, 1989, pp. 115-184; PÉrEz SolA, N., La regulación constitucional del referéndum, Universidad de Jaén, Jaén, 1994, p. 13 y ss.; LÓPEZ GONZÁLEZ, J. L., El referéndum en el sistema español de participación política, Universidad politécnica de Valencia, Valencia, 2005, p. 10 y ss. 
iniciativa le corresponde al Presidente del Gobierno, previa autorización del Congreso de los Diputados adoptada tras debate de totalidad por mayoría absoluta. Esta mayoría, no prevista en el Art. $92 \mathrm{CE}$, es impuesta por la Ley orgánica reguladora del referéndum con base en el Art. 79.2 CE, buscando lograr el consenso y favorecer un control de oportunidad por parte de la oposición. La convocatoria a cargo del Rey tampoco está exenta de polémica, no tanto por su consideración de acto debido, sino por realizarse, al determinarlo así la Ley orgánica de desarrollo, mediante Real Decreto acordado en Consejo de ministros y refrendado por su Presidente, cuando, según la Constitución, debería dejarse en manos del Rey con refrendo del Presidente del Gobierno. La ciudadanía, por tanto, queda fuera de la propuesta, que, centralizada en el Presidente del Gobierno, no excluye, sin embargo, al Congreso, a través de su necesario consentimiento. ¿Iniciativa, entonces, parlamentaria, como propugna Pedro Cruz Villalón, o gubernamental, como defiende, entre otros, Nicolás Pérez Sola? Quizás hablar de una iniciativa compleja sería lo más ajustado a la realidad, puesto que la intervención de ambos, Presidente del Gobierno y Congreso, resulta imprescindible. No contar con otros sujetos para ejercer la iniciativa o no exigir una mayoría parlamentaria más elevada para la autorización propicia que pueda pervertirse el uso del referéndum, por ejemplo, si el Presidente del Gobierno lo pone en marcha para consolidar su posición política frente a la oposición o como alternativa a la cuestión de confianza, potenciando su vis plebiscitaria, en el peor sentido de la expresión, en detrimento de su dimensión participativa.

Consultivo, porque su resultado jurídicamente no es vinculante, al margen de la dificultad que desde un punto de vista político suponga desoír la respuesta de la ciudadanía. Por eso hay quien hace depender el grado de vinculación del referéndum de que el resultado sea más o menos inequívoco, como el Profesor Ramírez; quien considera, como el Profesor De Esteban, que el resultado del referéndum siempre obliga, de modo que en caso de respuesta negativa se debe revocar la decisión o incluso convocar elecciones cuando la pregunta es relevante para el programa de gobierno, como sugiere el Profesor Oliver; o quien estima, como el Profesor Manuel Aragón, que el término consultivo equivale a no ratificador o no sancionador, ya que la decisión tomada con anterioridad a la consulta debe ser luego adoptada con carácter definitivo por el órgano competente, sin que el Cuerpo electoral lo sustituya, pues en su caso todo lo más podría vetar su actuación.

El Art. 92 CE remite, por último, a una Ley orgánica la regulación de las condiciones y el procedimiento de las distintas modalidades de referéndum previstas en la Constitución, sin embargo esta ley, la Ley orgánica 2/1980, no se ocupa de todos por igual, centrándose principalmente en los que tienen por objeto el acceso a la autonomía. Respecto de los que nos ocupan, los del Art. $92 \mathrm{CE}$, pocas novedades. La exigencia de mayoría absoluta en el Congreso para su autorización, su convocatoria por el Rey mediante Real Decreto acor- 
dado por el Consejo de Ministros que ha de contener el texto íntegro de la decisión política objeto de consulta, la claridad en la formulación de la pregunta, la fecha de la votación entre los treinta y ciento veinte días posteriores a la publicación oficial del Real Decreto y en lo demás su sometimiento a un régimen común al resto de consultas, que no resulta siempre lo más idóneo. Nada que decir respecto de la prohibición de celebración del referéndum o la suspensión del ya convocado si en alguno de los territorios en los que se va a realizar la consulta se ha declarado un estado de excepción o sitio, si no han pasado noventa días desde su levantamiento, si faltan noventa días para la celebración de elecciones parlamentarias, locales u otro referéndum o si no han trascurrido aún esos mismos noventa días desde su celebración, pues en un supuesto es imprescindible la plena vigencia de los derechos fundamentales como garantía para la celebración de la consulta y en otro se pretende evitar que se solape con otros instrumentos de participación ciudadana. Otras equiparaciones son difícilmente justificables. La circunscripción provincial, cuando en el caso del referéndum del Art. $92 \mathrm{CE}$ es única, en tanto el Cuerpo electoral independientemente de donde emita su voto cumple la misma función, decidir sobre una cuestión de trascendencia política; la remisión a las normas de régimen electoral general o el protagonismo desmedido de los grupos políticos con representación parlamentaria o los que hubieran obtenido al menos un tres por ciento de los sufragios válidamente emitidos en el ámbito a que se refiera la consulta en las últimas elecciones generales al Congreso. Serán ellos quienes accedan en campaña a los espacios gratuitos de propaganda en medios públicos y puedan activar el recurso contenciosoelectoral contra los acuerdos sobre los resultados del escrutinio general que tras la votación adopten las Juntas electorales provinciales, a las que también corresponde la proclamación de resultados, sin perjuicio de que la Junta electoral central realice un resumen a la vista de las actas que le remitan, declare oficialmente esos resultados, los comunique a los Presidentes del Gobierno, Congreso y Senado y disponga su publicación oficial. Choca que primero se quiera marcar las distancias entre el proceso electoral y el refrendatario, cuando luego sus partícipes son los mismos, los grupos políticos, cerrando la puerta a otras agrupaciones ciudadanas que pueden puntualmente posicionarse a favor o en contra de la decisión política de especial trascendencia sobre la que el Cuerpo electoral está llamado a pronunciarse. Si el Presidente del Gobierno con la autorización de la mayoría del Congreso es el único que puede impulsar la consulta y luego en el debate previo al pronunciamiento ciudadano la voz cantante la llevan los grupos políticos presentes en el Parlamento, el referéndum ni siquiera es un complemento a la democracia representativa, es lo mismo, no entendiéndose entonces las suspicacias que despertó su implantación. En democracia tan relevante es decidir como poder provocar la toma de la decisión e intervenir en la discusión en igualdad de condiciones, lo que no se consigue precisamente descafeinando el referén- 
dum como instrumento de participación hasta hacerle perder en gran medida su sentido ${ }^{3}$.

Son muchas las cuestiones que la Constitución y la Ley orgánica dejan en el tintero, desde el alcance del objeto del referéndum hasta la exigencia de un quorum de participación o de un número mínimo de votos favorables para que la cuestión planteada prospere, pasando por si es posible reiterar la pregunta de ser rechazada y en qué plazos, pero, sin duda, una de las más relevantes es la de su ámbito territorial. El Art. 92 CE ni determina expresamente cuál es este, ni tampoco prohíbe que puedan realizarse consultas sobre cuestiones políticas de especial trascendencia de alcance inferior al estatal como el autonómico o el local ${ }^{4}$. Que esto sea posible parece deducirse del Art. 149.1.32 CE cuando, en la línea de desconfianza habitual en este asunto confiere al Estado la competencia exclusiva en lo que a la autorización para la convocatoria de consultas populares por vía de referéndum respecta. Si ésta sólo correspondiera al Estado no tendría sentido mencionar la autorización en el reparto de competencias, como tampoco parece, pues nada se dice, que la autorización se circunscriba a los referéndums de relevancia territorial -de aprobación y reforma estatutaria- expresamente previstos en la Constitución, según señala la STC 31/2010, de 28 de junio. Igualmente se debe subra-

${ }^{3}$ Sobre la regulación del Art. 92 CE, CRUz Villalón, P., «El referéndum consultivo como modelo de racionalización constitucional», Revista de Estudios políticos, $\mathrm{n}^{\circ} 13$, 1980, pp. 145-168; Linde Paniagua, E., Herrero Lera, M., «El referéndum...», ob. cit., pp. 17-48 y, de los mismos autores, «Comentario a la Ley orgánica de modalidades de referéndum», Revista de Derecho Político, nº 6, 1980, pp. 83-105; Oliver Araujo, J., «El referéndum...», ob. cit., pp. 115-184; PÉREZ SOLA, N., La regulación... ob. cit., p. 13 y ss.; Aragón ReYes, M., Constitución y democracia, Tecnos, Madrid, 1989, p. 127 y ss.; LÓPEz GonzÁlez, J. L., El referéndum ... ob. cit., p. 10 y ss. y, del mismo autor, «El referéndum nacional consultivo sobre decisiones políticas de especial trascendencia», Cuadernos de la Cátedra Fadrique Furió Ceriol, no 38-39, 2002, pp. 207-218 y «El referéndum consultivo sobre decisiones políticas de especial trascendencia: reflexiones desde el principio democrático en relación al referéndum sobre la Constitución europea», Revista de Derecho Político, $\mathrm{n}^{\circ}$ 65, 2006, pp. 233-256; MARTín NúÑEZ, E., «El referéndum y las consultas populares en las Comunidades Autónomas y municipios», Revista vasca de Administración pública, $\mathrm{n}^{\circ}$ 94, 2012, pp. 95-131.

${ }^{4}$ De los trabajos parlamentarios puede extraerse que el ámbito territorial de la consulta prevista en el Art. $92 \mathrm{CE}$ es el estatal, ya que durante su tramitación se rechazó en el Senado una enmienda, la $n^{\circ}$ 999, defendida por el Sr. Monreal, del Grupo de socialistas vascos, que propugnaba que las decisiones políticas que afectaran a una Comunidad autónoma fueran sometidas a referéndum consultivo en ese territorio.

5 Aguado Renedo, C., «El referéndum autonómico», en Matía Portilla, F. J. (dir.), Pluralidad de ciudadanos, nuevos derechos y participación democrática, Cuadernos y Debate, CEPC, Madrid, 2011, pp. 389-419, explica la competencia del Art.149.1.32 CE por el temor de que la voluntad general, es decir, «la que, bajo el concepto de soberanía nacional, conforma el pueblo español en su conjunto ex art. 1.2 CE» se vea condicionada por «sólo una fracción del mismo» 
yar el lugar preeminente que el constituyente otorga a la participación y al pluralismo en los Arts. 1, 9.2 y $23 \mathrm{CE}$, en coherencia con dos de los principios estructurales de nuestro ordenamiento, el estado democrático y el estado social, de modo que una interpretación sistemática que tenga a estos elementos en cuenta puede permitir la aparición de otros mecanismos de participación directa de creación legal o estatutaria, siempre que respeten las restricciones explícitas que la Constitución señala y el lugar complementario y excepcional en que esta los coloca respecto de los instrumentos de democracia representativa, como se reconoce en la STC 103/2008, de 11 de septiembre $^{6}$. En definitiva, los Estatutos pueden atribuir a sus Comunidades Autónomas cualquier competencia que no pertenezca al Estado y a tenor del Art. 149 $\mathrm{CE}$, a este le corresponde autorizar la convocatoria de referéndums y fijar las bases tanto del régimen jurídico de las Administraciones públicas y del procedimiento administrativo común, como de las condiciones que garanticen la igualdad de todos los españoles en el ejercicio de los derechos y en el cumplimiento de los deberes constitucionales.

Así actualmente en los Estatutos de algunas Comunidades, como es el caso de Asturias -Art. 11-, Canarias -Art. 32-, La Rioja -Art. 9-, Murcia -Art. 11-, Castilla León -Art. 71-, Islas Baleares -Art. 31-o la Comunidad Valenciana -Art. 50-, se asume en el marco de la legislación básica del Estado la competencia de desarrollo legislativo y ejecución del sistema de consultas populares en su ámbito, de conformidad con lo que disponga la ley prevista en el Art. 92.3 CE y las demás leyes del Estado, correspondiéndole a éste la autorización de su convocatoria; los ciudadanos de Castilla y León y de las Islas Baleares, y también los de Andalucía y Cataluña, pueden promover la convocatoria de la consulta en los términos que establezcan las leyes. Otros Estatutos, sin embargo, prefieren calificar de exclusiva una competencia que describen de modo diverso. El Art. 9 del Estatuto de Extremadura se refiere al régimen y convocatoria de consultas populares diferentes al referéndum, mientras que el Art. 78 del Estatuto de Andalucía alude al establecimiento del régimen jurídico, las modalidades, el procedimiento, la realización y la convocatoria por la Comunidad o por los entes locales en el ámbito de sus competencias de encuestas, audiencias públicas, foros de participación y cualquier otro instrumento de consulta popular, con excepción del referéndum; salvedad esta que encontramos con otras redacciones en el Art. 71 del Estatuto de Aragón, que excluye de su competencia la regulación del referéndum y lo previsto en el Art. 149.1.32 CE, o en el Art. 122 del Estatuto de Cataluña, que descarta la asunción de lo previsto en el Art. 149.1.32 CE. Fórmulas similares,

${ }^{6}$ Así también lo subraya Pérez Sola, N., La regulación... ob. cit., p. 13 y ss. o URIARTE TORREALDAY, R., «Notas sobre la admisibilidad constitucional de consultas populares de ámbito autonómico», Revista vasca de Administración Pública, $\mathrm{n}^{\circ} 82,2008$, pp. 227-257. 
pero con distinto alcance, pues si la primera parece rechazar cualquier competencia de la Comunidad Autónoma en materia de referéndums, la segunda parece asumir a sensu contrario competencias ejecutivas en materia de referéndum y la última, la más expansiva, tan sólo deja en manos del Estado la autorización de la convocatoria del referéndum. Por el contrario, Galicia, Cantabria, País Vasco, Navarra, Madrid y Castilla-La Mancha no asumen ningún título competencial sobre esta materia ${ }^{7}$.

Salta a la vista que estatutariamente se quiere establecer una distinción entre referéndums y consultas populares de otra índole, al suponer que respecto de estas últimas el ámbito de actuación de las Comunidades sería mucho más amplio, incluso en lo que a su convocatoria se refiere, puesto que quizás no necesitarían de autorización estatal. Resulta entonces determinante separar uno y otro concepto. Este deslinde, objeto de numerosos estudios doctrinales, ya ha sido realizado, por otra parte, por el Tribunal Constitucional en sus SSTC 76/1994, de 14 de marzo, 119/1995, de 17 de julio, $103 / 2008$, de 11 de septiembre y $31 / 2010$, de 28 de junio. En ellas el referéndum se define como una especie del género consulta popular cuya peculiaridad no radica en cuál ha de ser su norma reguladora, su objeto, su finalidad o el grado de vinculación de su resultado, sino en una cuestión de naturaleza orgánico-procedimental. El referéndum, a diferencia del resto de consultas populares, es manifestación del ejercicio del derecho fundamental de participación política directa del Art. $23 \mathrm{CE}$ y fruto de la actuación, no de cualquier grupo de ciudadanos con intereses concretos, sino del Cuerpo electoral, que debe pronunciarse sobre el asunto público que se le someta conforme a un procedimiento electoral que asegure la veracidad de ese pronunciamiento, al

${ }^{7}$ Bueno ArmiJo, A., «Consultas populares y referéndum consultivo: una propuesta de delimitación conceptual y de distribución competencial», Revista de Administración pública, $\mathrm{n}^{\circ} 177,2008$, pp. 195-228, destaca como, a pesar de la diferente regulación estatutaria, en la práctica la situación en todas las Comunidades se equiparó al entender que las competencias autonómicas en materia de consultas populares se referían a las de ámbito local, lo que permitió incluso a las Comunidades que no habían asumido específicamente esta competencia desarrollar normativamente esas consultas con base en su título competencial sobre régimen local. Lo mismo sucedería, a su entender, cuando la consulta se incardina en un procedimiento administrativo con base en la competencia sobre desarrollo del régimen jurídico de las instituciones de autogobierno, sin perjuicio de la competencia estatal sobre las bases del régimen jurídico de las Administraciones públicas y del régimen administrativo común. Incluso, dando un paso más, URIARTE TORREALDAY, R., «Notas...» ob. cit., pp. 227-257, considera que las consultas populares no son una materia nueva y basta con tener competencia sobre el objeto de la consulta para que la Comunidad Autónoma proceda a su regulación con apoyo en la potestad de autoorganización vinculada al principio democrático. Nada que ver con la exigencia del Tribunal Constitucional, en su STC 103/2008, de 11 de septiembre, de una competencia expresa y específica en esta materia y la negativa a aceptar cualquier título competencial implícito que pudiera servir de base a las mismas. 
estar basado en el censo, gestionado por la Administración electoral y asegurado con garantías jurisdiccionales específicas. Las demás consultas populares, por tanto, son instrumentos de participación, aunque no expresión del derecho fundamental del Art. $23 \mathrm{CE}$, en los que sujetos no coincidentes con el Cuerpo electoral dan su opinión sobre asuntos de interés público a través de procedimientos que no reúnen las características y garantías del proceso electoral $^{8}$. En palabras del Tribunal Constitucional, en sus SSTC 103/2008, de 11 de septiembre, y $31 / 2010$, de 28 de junio, «caben, pues, consultas populares no referendarias mediante las cuales se recaba la opinión de cualquier colectivo sobre cualesquiera asuntos de interés público a través de cualesquiera procedimientos distintos de los que cualifican una consulta como referéndum y con los límites materiales a los que también hicimos referencia en la STC 103/2008 (FJ 4) respecto de todo tipo de consultas, al margen de la prevista en el Art. 168 CE».

¿Qué normas deben regular las consultas no referendarias y los referéndums autonómicos? Resulta evidente que si las Comunidades han asumido competencia legislativa en materia de consultas populares no hay inconveniente en que una norma autonómica se encargue de esta regulación cuando no se trate de referéndums; con qué alcance vendrá determinado por cuál sea la finalidad de la consulta, pues, por ejemplo, si pretende incardinarse en un procedimiento administrativo, la normativa autonómica habrá de respetar lo dispuesto por la normativa estatal reguladora de las bases sobre el régimen jurídico de las Administración Públicas y el procedimiento administrativo común, como tendría que estar a lo que disponga la Ley de bases de régimen local cuando las consultas incidan en el ámbito local en vez del autonómico -Art. 149.1.18 CE-9 ${ }^{9}$. Así lo entiende la STC 31/2010, de 28 de junio, en la que, refiriéndose a las encuestas, audiencias públicas y foros de participación a los que alude el Art. 122 del Estatuto de Cataluña ciñéndolos al ámbito de competencias autonómicas, considera que «no puede haber afectación alguna del ámbito competencial privativo del Estado. En particular, tampoco del título competencial atribuido por el Art. 149.1.18 CE... La exclusividad del

8 Específicamente sobre referéndums de ámbito territorial, véase, CoRCUERA ATIENZA, J., «Soberanía y autonomía. Los límites al derecho a decidir (Comentario de la STC 103/2008)», Revista española de Derecho Constitucional, ${ }^{\circ}$ 86, 2009, pp. 303341; Bueno ArmiJo, A., «Consultas populares...» ob. cit., pp. 195-228; LóPez BASAGUREN, A., «Sobre referéndum y Comunidades Autónomas. La ley vasca de la «consulta» ante el Tribunal Constitucional (consideraciones con motivo de la STC 103/2008)», Revista d'Estudis autonomics i federals, $\mathrm{n}^{\circ}$ 9, 2009, pp. 202-238; AguAdo RENEDO, C., «El referéndum...»ob. cit., pp. 389-419; MARTín NúÑ̃E, E., «El referéndum...»ob. cit., pp. 95-131.

9 Andalucía -Ley 2/2001-, Navarra -Ley foral 27/2002- o la Comunidad valenciana -Ley 11/2008-, por ejemplo, tienen leyes específicas sobre consultas o genéricas sobre participación ciudadana en las que se contemplan figuras de este tipo. 
Art. 122 EAC ha de serlo, por tanto, sin perjuicio de la competencia estatal relativa a las bases del régimen jurídico de las Administraciones públicas». La licitud constitucional depende, en conclusión, no de la materia afectada, perfectamente asumible, sino del alcance de competencia que recae sobre ella, puesto que lo que se define como exclusivo se reinterpreta como compartido para poder ser aceptado en términos constitucionales.

Cosa distinta son los referéndums autonómicos. Como ya hemos señalado, el referéndum es una manifestación del derecho de participación política directa del Art. $23 \mathrm{CE}$, por lo que el desarrollo de este derecho fundamental ha de hacerse por Ley orgánica, según dispone el Art. $81 \mathrm{CE}$, y la regulación de su ejercicio por ley ordinaria, a tenor del Art. $53 \mathrm{CE}$, estatal o autonómica, dependiendo de lo que establezcan las normas de reparto de competencias. Estas atribuyen al Estado en esta materia específicamente la autorización de la convocatoria de referéndums -Art. 149.1.32 CE-y genéricamente la regulación de las condiciones básicas que garanticen la igualdad de todos los españoles en el ejercicio de los derechos y en el cumplimiento de los deberes constitucionales -Art. 149.1.1 CE-y las bases del régimen jurídico de las Administraciones púbicas y el procedimiento administrativo común -Art. 149.1. 18 CE-, que también aquí podrían ser de aplicación. La reserva, sin embargo, que el Art. $92 \mathrm{CE}$ realiza en favor de una Ley orgánica en principio alcanza tan sólo a la regulación de las condiciones y el procedimiento de las distintas modalidades de referéndum previstas en la Constitución y ese no parece ser el caso de los referéndums autonómicos. De este modo pareció entenderlo el legislador, al no incluirlos en la Ley orgánica 2/1980, que paradójicamente sí alude a los referéndums municipales para cuya regulación reenvía a la legislación de régimen local. Esto no quita que las Comunidades Autónomas que asuman competencia en la materia deban respetar lo que en ella se dispone en cuanto desarrolle el derecho fundamental del Art. $23 \mathrm{CE}$, sin olvidar la función que cumple en este punto la Ley orgánica de régimen electoral general. Si esto es así los Estatutos por razones distintas -para respetar bien una reserva constitucional, bien una distribución de competencias- nunca podrían atribuir a la Comunidad Autónoma en materia de referéndum ni la competencia de desarrollo legislativo del derecho de participación política en lo que a estas consultas se refiere, ni la autorización de su convocatoria, facultad, esta última, incardinada dentro de la competencia de ejecución; pero sí les sería posible conferir la regulación del ejercicio de esta expresión del Derecho fundamental del Art. 23 CE dentro del respeto a la competencia estatal sobre lo básico que podría jugar vía Art. 149.1.1 o vía Art. 149.1.18 CE.

Desde este planteamiento que admite con ciertas limitaciones que los Estatutos permitan la regulación autonómica de los referéndums en su ámbito territorial y dentro de sus competencias, el Art. 122 del Estatuto de Cataluña, como dijimos, expresamente afirma la competencia exclusiva de la 
Generalitat sobre el establecimiento del régimen jurídico, las modalidades, el procedimiento, la realización y la convocatoria en el ámbito de sus competencias de encuestas, audiencias públicas, foros de participación y cualquier otro instrumento de consulta popular, con excepción de lo que el Art. 149.1.32 CE prevé en lo que a la autorización por el Estado de la convocatoria de referéndum se refiere. De manera implícita y residual puede entenderse, por tanto, que la Generalitat también asume el establecimiento del régimen jurídico, modalidades procedimiento, realización y convocatoria del referéndum, al tratarse de otro instrumento de consulta popular, dejando a salvo la mencionada autorización estatal de su convocatoria. Sin embargo, la STC 31/2010, de 28 de junio, al hilo del enjuiciamiento de este precepto, descarta que la expresión «cualquier otro instrumento de consulta popular» comprenda al referéndum e interpreta el Art. 149.1.32 CE de manera expansiva, entendiendo que no sólo le corresponde al Estado autorizar la convocatoria de cualquier referéndum, sino también su «entera disciplina», es decir, «su establecimiento y regulación», quedando únicamente en manos de la Generalitat, con las restricciones señaladas, las competencias anteriormente mencionadas sobre toda consulta popular que no tenga esa naturaleza ${ }^{10}$. La razón, como ya adelantó el Tribunal en su STC 103/2008, de 11 de septiembre, es que la Ley orgánica 2/1980 sobre regulación de las distintas modalidades de referéndum no es sólo «la llamada por el Art. 92.3 CE para regular las condiciones y el procedimiento de las distintas modalidades de referéndum previstas en la Constitución», sino que es «la única ley constitucionalmente adecuada para el cumplimiento de otra reserva, añadida a la competencial del Art.149.1.32 CE: la genérica del Art. 81 CE para el desarrollo de los derechos fundamentales, en este caso el derecho de participación política reconocido en el Art. $23 \mathrm{CE} »{ }^{11}$.

${ }^{10}$ Ello incide en la ya aprobada Ley catalana 4/2010 de consultas populares por vía de referéndum, que ha sido objeto de un recurso de inconstitucionalidad sobre el que el Tribunal Constitucional aún no se ha pronunciado. Hasta el momento tan sólo ha levantado en su ATC 87/2011 la suspensión automática de sus artículos relativos al referéndum autonómico, al entender, sin prejuzgar a quién corresponde la competencia de regulación de los referéndums, que el interés general está asegurado, en tanto cualquier referéndum autonómico que quisiera convocarse necesitaría de autorización estatal, como la propia Ley catalana reconoce.

11 Sobre la regulación del referéndum en el Estatuto catalán, mostrándose partidarios de la misma con base en un título competencial respetuoso de las competencias estatales y de las reservas constitucionales y críticos con la posterior sentencia del Tribunal Constitucional, CASTEllà AndReu, J. M., «La competencia en materia de consultas populares por la vía de referéndum en la STC 31/2010 sobre el Estatuto de Cataluña», Revista catalana de Dret public, número especial sentencia 31/2010 del Tribunal Constitucional sobre el Estatut d'autonomia de Catalunya, 2010, p. 308; MARTín NúÑEZ, E., «Comentario a la Sentencia sobre el Estatuto. Competencia en materia de consultas populares (Art. 122 
Si en la STC 103/2008, de 11 de septiembre, parece admitirse los referéndums autonómicos siempre que los Estatutos asuman expresamente ese título competencial, si se considera que este tipo de consultas son manifestación del derecho fundamental del Art. $23 \mathrm{CE}$, si tal derecho debe ser desarrollado por una ley orgánica, según el Art. $81 \mathrm{CE}$, sin que tenga que agotar toda la regulación sobre el mismo, y si la Ley orgánica del Art. 92 CE tan sólo está obligada a regular las modalidades de referéndum previstas en la Constitución, no se comprende por qué sólo la Ley orgánica del Art. 92 puede satisfacer la reserva del Art. $81 \mathrm{CE}$, por qué no puede haber una Ley orgánica que se ocupe de los referéndums no previstos en la Constitución en los aspectos que atañan al desarrollo del mencionado derecho y por qué no puede existir leyes ordinarias que regulen aquellos aspectos relativos al referéndum autonómico que no sean en sentido estricto desarrollo del derecho fundamental del Art. 23 CE. Salvo por economía legislativa, nada en la Constitución impide que una Ley orgánica distinta a la que se refiere el Art. $92 \mathrm{CE}$ pueda desarrollar el derecho fundamental del Art. $23 \mathrm{CE}$ en lo relativo a los referéndums autonómicos, sin perjuicio de que también pueda reformarse la vigente Ley orgánica e incluir en ella una referencia a los mismos que salve el necesario desarrollo del derecho fundamental a través de este procedimiento. Las dos opciones, a nuestro entender, son constitucionalmente admisibles y en uno y otro caso sería posible que el legislador ordinario, estatal o autonómico, según a quién corresponda la competencia, pudiera regular aquellos aspectos que caen fuera del desarrollo del derecho; buena prueba de ello es que la Ley de bases de régimen local así lo hace para los referéndums municipales o que, en otra manifestación del Art. $23 \mathrm{CE}$, existen leyes electorales autonómicas además de la Ley orgánica de régimen electoral general ${ }^{12}$.

En definitiva, con la última interpretación realizada por el Tribunal Constitucional, cualquier regulación normativa de los referéndums autonómicos por las Comunidades Autónomas interesadas pasa por dos caminos. O reformar la Constitución, incluyendo en el Art. $92 \mathrm{CE}$ una referencia expresa a estas consultas y al desarrollo por ley orgánica del derecho de participación del que son manifestación, sin perjuicio de que la concreción de las condicio-

EC)», Revista catalana de Dret public, número especial sentencia 31/2010 del Tribunal Constitucional sobre el Estatut d'autonomia de Catalunya, 2010, p. 316 y «El referéndum...» ob. cit., pp. 95-131; BossaCOMA I BusQueTs, P., «Competències de la Generalitat de Catalunya sobre regulació i convocatoria de consultes populars», Revista d'Estudis autonómics i federals, $\mathrm{n}^{\mathrm{o}} 15$, pp. 241-286.

12 Sobre este particular, véase Aguado Renedo, C., «Referéndum autonómico y jurisprudencia constitucional», Teoría y realidad constitucional, $\mathrm{n}^{\circ} 28,2011$, pp. 543-554; Corcuera AtienZA, J., «Soberanía...» ob. cit., pp. 303-341. Desde otros planteamientos, proclives a reformar e incluir los referéndums autonómicos en la Ley orgánica, también se muestran CASTEllà Andreu, J. M., «La competencia...» ob. cit., p.308; Martín NúÑEZ, E., «Comentario...» ob. cit., p. 316 y «El referéndum...» ob. cit., pp. 95-131. 
nes de su ejercicio pueda corresponder a las leyes autonómicas si estatutariamente así se contempla, subrayando con ello el alcance estricto que ha de darse en el Art. 149.1.32 CE al término autorizar, o, todo lo más, y dependiendo del caso, por aprobar una ley orgánica de transferencias del Art. 150.2 CE que delegue en la Comunidad Autónoma la regulación e incluso la autorización de la convocatoria de estas consultas ${ }^{13}$.

\section{ALGUNAS PROPUESTAS DE REFORMA}

\subsection{Sobre la necesidad de la reforma}

No se puede negar que la exigua configuración constitucional de los instrumentos de democracia directa, entre ellos el referéndum, ha satisfecho el objetivo perseguido por los constituyentes españoles, contribuyendo junto a otros factores a la consolidación de una democracia representativa y de un sistema de partidos, que, sin embargo, han sufrido en los últimos tiempos un considerable deterioro. Las causas son complejas y exceden con mucho el objeto de este trabajo. No obstante, de igual manera que primero se impuso una configuración restrictiva de los mecanismos de democracia directa, en una reforma que busque su potenciación puede estar ahora la clave que permita corregir algunas de las distorsiones apreciadas en la democracia repre-

13 En el Informe del Instituto de Estudios autonómicos de Cataluña de 11 de marzo de 2013 sobre los procedimientos legales a través de los que los ciudadanos y ciudadanas de Cataluña pueden ser consultados sobre su futuro político colectivo se sugieren varias posibilidades para este supuesto concreto, todas ellas inadmisibles si se entiende que el objeto mismo de la pregunta no puede abordarse más que el en marco de una reforma constitucional al verse afectados la soberanía y la unidad del ordenamiento español. No sólo se mencionan las opciones propuestas en el texto, de las que la delegación del Art. 150.2 CE contaría en este caso con la dificultad de determinar si estamos ante una competencia por su naturaleza susceptible de transferencia o delegación, sino también la posible reforma de la ley orgánica reguladora de las distintas modalidades de referéndum, la aprobación de una nueva que incorpore al que nos ocupa, la posibilidad de hacer uso de la Ley catalana 4/2010, válida y aplicable en tanto el Tribunal Constitucional aún no se ha pronunciando sobre la misma y ha levantado su suspensión, o la convocatoria con el mismo objeto de otro tipo de consulta no referendaria, siendo conscientes de que en ambos casos existe el inconveniente de que el objeto de la consulta, sea cual sea su naturaleza, tiene que encajar en el ámbito de competencias autonómicas y de que la pregunta que se pretende excede de las mismas, a no ser que en sentido amplio se vincule con la facultad de iniciativa legislativa y de reforma constitucional de la que disfrutan las Comunidades Autónomas. Sin embargo el Dictamen 15/2010 del Consejo de Garantías Estatutarias respecto a la Propuesta de iniciativa popular de consulta por vía de referéndum sobre la independencia de la nación catalana no parece aceptar esta interpretación, exigiendo en ese supuesto que el objeto de la consulta se mueva dentro de las competencias autonómicas en sentido estricto. 
sentativa, satisfaciendo las legítimas aspiraciones de una ciudadanía madura que ambiciona más y mejor democracia. Estas carencias no parece posible subsanarlas reinterpretando la regulación actual desde la óptica de un principio estructural democrático que obligase a reforzar la participación política. En ningún caso este tipo de relecturas podría hacer decir a la Constitución lo que no dice, puesto que, por mucho que reconozca el derecho de los ciudadanos a participar en asuntos públicos directamente o por medio de representantes, de una interpretación sistemática de sus preceptos parece clara la voluntad de que la democracia representativa prevalezca sobre la directa. Cualquier salto cualitativo exigiría una reforma de la Constitución que pudiera, en este caso, establecer nuevas modalidades de referéndum con incidencia en la organización del poder público o en la posición de los distintos órganos constitucionales y prefigurar los procedimientos a seguir por exigencia de un estado de derecho equiparado, en tanto principio estructural, al estado democrático $^{14}$.

En definitiva, la mejora de la calidad de un estado democrático hasta el momento eminentemente representativo y deficitario de elementos propios de una democracia directa pasa por una reforma constitucional que reduzca el gran desequilibrio existente entre estos dos modos de ejercicio de la soberanía.

Pero no toda revisión con incidencia en el referéndum, incluso las que admiten que los ciudadanos insten la convocatoria de una consulta que tenga por objeto la ratificación de una ley o la derogación de una ya vigente, tiene por qué significar un avance democrático de calado. Las apariencias pueden engañar y lo relevante es su articulación concreta. Multiplicar la pluralidad de canales de participación/decisión, proteger a las minorías, verificar la conformidad entre representantes y representados o dinamizar la forma de gobierno deben ser algunos de los objetivos de la reforma ${ }^{15}$. La desconfianza en los partidos y en las instituciones representativas obliga a introducir cambios de importancia. Las nuevas modalidades de referéndum pueden canalizar jurídicamente el descontento, acercar al ciudadano a los asuntos públicos y

${ }^{14}$ Aragón Reyes, M., Constitución... ob. cit. p. 102 y ss., afirma que no hay principio democrático sobre la Constitución porque no hay derecho fuera del derecho. Junto a la democracia como principio jurídico de la Constitución, con un contenido procedimental que opera como fuente de validez que permite al Pueblo constituyente disponer de la Constitución sin límite material, la democracia puede ser un principio jurídico en la Constitución, con un contenido material, procedimental y estructural que se proyecta en distintas reglas constitucionales y opera como principio de legitimidad de la Constitución. En su opinión, «profundizar en la democracia es el único camino para que se aleje toda posibilidad de que la validez pueda algún día destruir la legitimidad».

${ }^{15}$ LuCIANI, M., «El referéndum, cuestiones teóricas y de la experiencia italiana», Revista catalana de Dret public, $\mathrm{n}^{\circ} 37,2008$, pp. 157-182, recuerda estas funciones que doctrinalmente se asocian a las distintas modalidades de referéndum. 
reducir la distancia entre gobernantes y gobernados ${ }^{16} \mathrm{o}$, en otras palabras, puede contribuir a completar la «democracia de elección» con una «democracia de expresión, implicación e intervención ${ }^{17}$.

Posiblemente Sieyes aún no esté del todo superado y siga vigente su cautela hacia unos ciudadanos que «no son tan capaces como los representantes de conocer el interés general e interpretar bajo esta perspectiva su propia voluntad $\rangle^{18}$. Cualquier reforma que no quiera defraudar debe configurar los mecanismos de democracia directa de tal modo que les sea posible alcanzar su finalidad. Por tanto no basta con diversificar la tipología de referéndums. Cuando quien impulsa la consulta e incita al Cuerpo electoral a pronunciarse es el Ejecutivo o el Legislativo y no la propia ciudadanía se desvirtúa en gran medida el valor democrático del referéndum y su vínculo con el pluralismo y la participación, por lo que habría que asegurar que la convocatoria realmente sea un acto de autolimitación que fomente la democracia directa y no una búsqueda de apoyo plebiscitario a una decisión ya tomada.

\subsection{Algunas propuestas sobre la mesa}

En la actualidad se encuentran en tramitación varias propuestas de reforma de la regulación del referéndum en España. Nos centramos en dos de ellas que se han puesto en marcha desde planteamientos similares.

La primera ha sido presentada por el Grupo parlamentario mixto y por el Grupo parlamentario «La Izquierda Plural» en esta legislatura, el trece de mayo de 2013, en el Congreso de los Diputados. Se trata de la Proposición de reforma constitucional para reforzar la participación política y el pluralismo en el régimen electoral ${ }^{19}$. Tras su calificación y admisión a trámite se encuentra en la fase de toma en consideración.

La iniciativa tiene un objeto más amplio que la mera modificación de la regulación del referéndum. Persigue profundizar en los dos elementos clave del estado democrático, la participación y el pluralismo político, mediante una reforma del régimen electoral general, que, a juicio de los proponentes, necesita mejorar su calidad democrática una vez alcanzado el objetivo para el que fue diseñado, esto es, consolidar la democracia representativa y el

${ }^{16}$ GICQUEL, J.-É., «Faut-il introduire en France le référendum législatif d'initiative populaire ?», Petites affiches, $\mathrm{n}^{\circ}$ 20, 2005, pp. 5-12; Nuss, P., «Référendum et initiative populaire en France ? De l'illusion en général et de l'hypocrisie en particulier», Revue $d u$ Droit Public, $\mathrm{n}^{\circ}$ 5, 2000, pp. 1441-1493.

17 RosanVallon, P., "Le mythe du citoyen passif», Le monde, 20 de junio de 2004.

18 SIEYES, E., Dire de l'abbé sur la question du veto royal à la séance du 7 septembre de 1789, Badouin, Paris, 1979.

19 Boletín Oficial de las Cortes Generales, Congreso de los Diputados, serie B, no 122 1, de 24 de mayo de 2013, cve: BOCG-10-B-122-1. 
sistema de partidos. En esta línea, buscando potenciar la proporcionalidad del sistema electoral y con ello la fiel representación del pluralismo en las instituciones, se pretende que la Comunidad Autónoma sea la circunscripción que elija un número de diputados en función de su censo; que el acceso al reparto de escaños se asegure a todas las candidaturas que hayan obtenido sufragios conforme a una proporcionalidad directa; o que todos los senadores sean designados por los parlamentos autonómicos atendiendo a la proporcionalidad territorial y a la pluralidad política. Para impulsar la participación política más allá de un momento electoral, en el que todas las candidaturas deben contar con igualdad de oportunidades, se quiere eliminar los límites materiales a los que hoy por hoy se somete a la iniciativa legislativa popular $\mathrm{y}$, en lo que a nosotros nos ocupa, ampliar los supuestos de convocatoria de referéndum.

En efecto, junto al imprescindible cambio de los Arts. 68, 69 y $87 \mathrm{CE}$ en el sentido apuntado, también se sugiere la reforma de los Arts. 167 y $92 \mathrm{CE}$, pues se propugna que toda revisión constitucional sea sometida a referéndum obligatorio y vinculante y que los supuestos de convocatoria de referéndums consultivos se incrementen con requisitos más flexibles. El nuevo Art. $92 \mathrm{CE}$ prevé la posibilidad de que los poderes y las administraciones públicas promuevan consultas vinculantes sobre asuntos de especial relevancia o interés para el conjunto de la ciudadanía, así como que las decisiones políticas puedan ser sometidas a referéndum consultivo. El referéndum, en materias de competencia estatal, será convocado por el Rey a propuesta del Presidente del Gobierno, previamente autorizado por el Congreso a petición de un cinco por ciento de los miembros del Congreso o del Senado o a iniciativa popular, con los requisitos establecidos para las iniciativas legislativas populares; cuando las materias sean de competencia autonómica, los Presidentes de las Comunidades autónomas podrán convocar referéndums consultivos, a petición de sus Asambleas legislativas o a iniciativa popular, de acuerdo con el procedimiento que se establezca en las leyes autonómicas. Las entidades locales, a través de sus Alcaldes o Presidentes, también podrán convocar referéndums consultivos en asuntos de interés local que regule la legislación básica sobre régimen local. Una ley orgánica, aprobada antes de seis meses tras la publicación de la reforma constitucional, deberá regular las condiciones, el procedimiento y los requisitos de las distintas modalidades de referéndum previstas en la Constitución.

Por otra parte, en una Asamblea legislativa autonómica, la Junta General del Principado de Asturias, el grupo parlamentario Izquierda Unida ha presentado el cinco de diciembre de 2012 una proposición de reforma, de las del Art. 166 CE en relación con el Art. 87.2 CE, específicamente de los Arts. $87.3,92$ y $166 \mathrm{CE}$, que ya ha sido tomada en consideración el veinticuatro de mayo de 2013, con los votos a favor de los grupos parlamentarios Izquierda unida, Socialista y Mixto y en contra de los grupos parlamentarios Popular y 
Foro Asturias, y trasladada a la Comisión de Presidencia, donde, tras la publicación de las enmiendas presentadas, se ha procedido a la designación de los miembros de la Ponencia. La propuesta, en realidad, como recuerda la propia exposición de motivos, hace suya la expresada primero en 2011 por los firmantes del manifiesto «Por la democracia directa» y luego por aquellos ciudadanos que ejercieron su derecho de petición ante diferentes Parlamentos autonómicos, entre ellos siete mil setecientas personas ante la Junta General, solicitando la puesta en marcha de una reforma constitucional que, asentada la democracia representativa, impulsara mecanismos de democracia directa como la iniciativa legislativa popular o las consultas populares en la línea de la Constitución de 1931, del anteproyecto de la vigente Constitución española o de otros ordenamientos de nuestro entorno -Italia, Irlanda, Dinamarca, Austria, Estados Unidos, Suiza, Alemania, por citar algunos ejemplos en lo que a los referéndums se refiere-. Estas influencias explican que la propuesta presentada por el grupo Izquierda Unida no sólo elimine los límites materiales a la iniciativa legislativa popular, incluida la reforma constitucional, manteniendo las quinientas mil firmas exigidas y la concreción por Ley orgánica de la regulación de su ejercicio, sino que también introduzca serias modificaciones en el Art. 92 CE. De una parte, junto al referéndum sobre decisiones políticas de especial trascendencia, se incorpora la figura del referéndum legislativo, cuyo objeto es la aprobación de leyes votadas por las Cortes aún no sancionadas o la derogación de leyes en vigor. En todo caso al Rey le corresponde convocar el referéndum a propuesta del Gobierno, a iniciativa de las Cámaras, de las Asambleas de tres Comunidades autónomas o de quinientos mil electores y su resultado será vinculante si en él participa la mayoría de quienes tengan derecho a hacerlo y es aprobado por la mayoría de los votos válidamente emitidos. Las condiciones del referéndum legislativo y constitucional, así como la iniciativa popular que puede impulsarlos, deberán ser reguladas por ley orgánica.

Visto lo visto, más allá de su intención de desarrollar estos instrumentos de participación directa, poco tienen en común ambas iniciativas y no nos estamos refiriendo al distinto alcance de las reformas proyectadas, mucho más extenso en el primer caso que en el segundo. Centrándonos estrictamente en las nuevas propuestas en torno al referéndum se aprecia una mayor ambición y un mayor rigor técnico en la presentada en la Junta General que en la del Congreso. Esta última no amplía la tipología de referéndums de ámbito estatal que ya pueden convocarse en la actualidad, esto es, consultivos con incidencia en la dirección política y de reforma constitucional, transformando tan sólo de potestativa a preceptiva la convocatoria de este último en el supuesto previsto en el Art. $167 \mathrm{CE}$. En efecto, la redacción que se sugiere del Art. $92 \mathrm{CE}$, tras comenzar mezclando con la consiguiente confusión diferentes instrumentos de participación no todos ellos necesariamente conectados con el Art. $23 \mathrm{CE}$, recordemos la alusión a la promoción de consul- 
tas por los poderes públicos sobre asuntos de especial relevancia o interés ciudadano a la que luego no vuelve a referirse, mantiene el referéndum consultivo sobre decisiones políticas al margen de su trascendencia, sin introducir otros nuevos. Se limita a explicitar su alcance territorial, nacional, autonómico o local, en función de a quién pertenezca la competencia sobre la cuestión objeto del mismo, pero sin plantearse la modificación del Art. 149.1.32 CE, por lo que por mucho que su convocatoria pueda dejarse en manos de los Presidentes de la Comunidad Autónoma, de Alcaldes o Presidentes de entes locales, en último término sigue siendo necesaria la autorización del Estado. La única aportación significativa parece ser la apertura de la solicitud de referéndum a las minorías parlamentarias y a la iniciativa popular. Sin embargo todo se queda en mera apariencia, pues en el ámbito estatal la última palabra la tiene la mayoría del Congreso, que es la que debe autorizar la propuesta de convocatoria del Presidente del Gobierno independientemente de quien la inste; paradójicamente no ocurre lo mismo en el ámbito autonómico donde la convocatoria por el Presidente de la Comunidad puede ser instada por la Asamblea legislativa, no por una minoría de la misma, y por iniciativa popular, sin que se mencione en este caso que deba ser autorizada por el Parlamento autonómico. La remisión a la legislación autonómica para regular el procedimiento de estos últimos referéndums tiene un alcance más que limitado, puesto que también se reenvía a una ley orgánica las condiciones, el procedimiento y requisitos de las distintas modalidades de referéndum previstas en la Constitución, entre ellas ahora también los autonómicos y los locales, ampliando la reserva más allá del mínimo impuesto por el Art. $81 \mathrm{CE}$ relativo al desarrollo del derecho fundamental del Art. $23 \mathrm{CE}$. Por todo ello, los avances en términos democráticos que se anuncian son escasos, no siempre están bien resueltos y parece que más que ofrecer una mejora en abstracto de la calidad democrática de nuestro sistema intentan dar respuesta a un problema concreto y de actualidad, lo que les lleva a hacer hincapié en la cuestión territorial.

No ocurre lo mismo con la propuesta de reforma constitucional que se está tramitando en Asturias. La incorporación de las modalidades de referéndum legislativo de ratificación y de abrogación sin límites materiales marcan un antes y un después, que pone de manifiesto la intención de potenciar la democracia directa sin hacer perder su preeminencia a la democracia representativa. Esta inclusión de nada serviría si la iniciativa se dejara en manos exclusivamente del Ejecutivo o de la mayoría que lo sustenta. Con independencia de que la propuesta de convocatoria corresponda al Gobierno, no a su Presidente, como en la actualidad, eliminando ese elemento presidencialista impropio de nuestro sistema, la petición corre a cargo del mismo número de electores que pueden ejercer la iniciativa legislativa popular y de tres Parlamentos autonómicos, con lo que se elimina el filtro de la autorización parlamentaria. Téngase en cuenta que son las Cámaras los otros sujetos que pue- 
den solicitar la convocatoria y no parece factible que la misma mayoría que ha aprobado una ley se arriesgue a que no sea ratificada por el Cuerpo electoral o proponga su derogación o que otra mayoría distinta promueva el referéndum abrogativo cuando podría por si misma dejar sin efecto la norma en cuestión. Permitir, por otra parte, a las minorías parlamentarias el impulso de estos referéndums de naturaleza legislativa sería una vía más sencilla en su articulación que la iniciativa popular cuando parezca necesario celebrar un referéndum ante un desacuerdo, aunque sea puntual, entre mayoría parlamentaria y Cuerpo electoral, pero también podría conducir, sin duda, a prácticas obstruccionistas, por lo que sería más idóneo eliminar la iniciativa parlamentaria, ya sea de la mayoría o de las minorías, puesto que ambas ya han tenido ocasión de intervenir en el procedimiento legislativo apoyando $\mathrm{u}$ oponiéndose a la ley y de lo que se trata es de que participen en la función legislativa sujetos distintos a los habituales. Positivo resulta el que se dé entrada a las Comunidades Autónomas a través de sus Parlamentos, no sólo en términos democráticos de pluralismo territorial, sino también desde un punto de vista de organización territorial del Estado, en tanto es una buena manera de implicar a las partes en decisiones que afectan al todo, asegurando que el interés general y no intereses particulares sea el móvil de su actuación con la exigencia de que la petición vaya avalada al menos por tres Asambleas legislativas. Ello no quita para que se eche en falta una referencia expresa que disipe cualquier duda de inconstitucionalidad sobre la celebración de otros referéndums de ámbito autonómico o local en los términos que la propia Constitución u otras normas a las que ella podría reenviar señalaran; en tanto nada se dice sobre la reforma del Art. 149.1.32 CE se entiende implícitamente que son posibles, siempre que los Estatutos u otras leyes estatales así lo prevean y el Estado autorice su convocatoria por el órgano competente. Pierde el referéndum su carácter consultivo cuando se alcanza el quorum de participación y de decisión que a la manera italiana se establece; en el caso de que la respuesta afirmativa no sea mayoritaria no se especifica si el referéndum puede llegar a reiterarse en los mismos términos y en qué plazos, lo que podría ser de cierta utilidad. No es descartable que de esas cuestiones pueda ocuparse la ley orgánica a la que la nueva redacción remite para determinar las condiciones del referéndum legislativo y constitucional; inexplicablemente se olvida de los referéndums sobre decisiones políticas, a los que también debería alcanzar la regulación ofrecida por dicha ley orgánica.

\subsection{Otras propuestas de lege ferenda}

Aunque de la crítica realizada a alguna de las proposiciones en tramitación ya podría deducirse qué propuestas, a nuestro entender, pueden parecer más convenientes, no está de más ofrecer una exposición sistemática de las mismas a modo de conclusión. 
La reforma debe dar respuesta a las deficiencias que se observan en la regulación actual y que afectan tanto al Estado democrático como al Estado autonómico. Una revisión, como las sugeridas hasta este momento, que sólo ponga el acento en una de esas dos perspectivas quedaría coja.

En términos democráticos parece necesario incrementar la tipología de referéndum en lo que a su naturaleza se refiere, incorporando aquellos que permitan a los ciudadanos intervenir en la función legislativa aprobando leyes votadas en las Cortes aún no sancionadas o derogando otras ya vigentes; la imposición de límites materiales tan estrictos como los que ahora rigen para la iniciativa legislativa popular haría perder su sentido a la reforma, pero al menos excluir esta clase de consultas cuando de la no aprobación o de la derogación de la norma se deriven responsabilidades internacionales para el Estado no parece descabellado. Su convocatoria debiera corresponder al Rey con refrendo del Presidente del Gobierno y ser realizada a propuesta del Gobierno a instancia de quinientos mil electores y cuatro Parlamentos autonómicos. Sólo abriendo la iniciativa, sobre todo a los ciudadanos, y además a las Comunidades autónomas en un número suficiente que garantice planteamientos generalistas, se consigue subrayar la dimensión participativa del referéndum. El referéndum sobre decisiones políticas de especial trascendencia también debería ser objeto de algún retoque, como el relativo al refrendo de la convocatoria por el Presidente del Gobierno, a la propuesta de convocatoria por parte del Gobierno y no de su Presidente o a la necesidad de mayorías cualificadas para su autorización en el Congreso. Igualmente, si no se quiere defraudar las expectativas ciudadanas, sea cual sea el objeto del referéndum, legislativo o de dirección política, parece conveniente afirmar su carácter vinculante y establecer una circunscripción única en la que durante la campaña puedan intervenir en condiciones de igualdad otros colectivos distintos a los grupos políticos con representación parlamentaria. Del mismo modo habría que indicar en todo caso que para entender aprobada la propuesta resulta imprescindible la participación de la mayoría del Cuerpo electoral y la obtención de la mayoría de los votos válidamente emitidos, prohibiendo en los supuestos de referéndum abrogativo o de referéndum sobre decisiones políticas de especial trascendencia instar una nueva consulta con un objeto idéntico al rechazado en un plazo que, a nuestro juicio, no debería ser inferior a dos años.

En términos también democráticos, porque indudablemente de pluralismo en su dimensión territorial se trata, pero con una clara incidencia en el modelo descentralizado español, habría que incluir una referencia, aunque fuera de mínimos, a los referéndums autonómicos e, incluso, a los locales, que les diera cobertura constitucional expresa. Debería señalarse que siempre que estatutariamente así se establezca y dentro del ámbito estricto de sus competencias las Comunidades Autónomas pueden celebrar referéndums equivalentes en cuanto a su tipología a los previstos en el plano estatal, co- 
rrespondiéndoles tanto su convocatoria, sin perjuicio de la necesaria autorización del Estado, como su regulación, que deberá respetar las reservas constitucionales y las competencias estatales existentes.

Con estas sugerencias, lejos de pretender ofrecer una respuesta inmediata y bajo presión a cuestiones de plena actualidad que necesitan de reflexión sosegada, se persigue poner sobre la mesa alternativas a la regulación vigente para contribuir a un debate que, a nuestro modesto entender, debe dirigirse no a resolver un problema puntual por trascendente que sea, sino a ofrecer una respuesta que sirva hoy y en el futuro a mejorar la calidad de un Estado democrático que corre el riesgo de resultar cada vez más irreconocible.

\section{BIBLIOGRAFÍA}

Aguado Renedo, C., «Referéndum autonómico y jurisprudencia constitucional», Teoría y realidad constitucional, $\mathrm{n}^{\circ} 28,2011$, pp. 543-554.

— «El referéndum autonómico», en Francisco Javier Matía Portilla (dir.), Pluralidad de ciudadanos, nuevos derechos y participación democrática, Cuadernos y Debate, CEPC, Madrid, 2011, pp. 389-419.

Aguiar de LuQue, L., Democracia directa y Estado constitucional, Edersa, Madrid, 1977.

Aragón Reyes, M., Constitución y democracia, Tecnos, Madrid, 1989.

Bossacoma i Busquets, P., «Competències de la Generalitat de Catalunya sobre regulació i convocatoria de consultes populars», Revista d'Estudis autonómics $i$ federals, $\mathrm{n}^{\circ} 15$, pp. 241-286.

Bueno ARMiJo, A., «Consultas populares y referéndum consultivo: una propuesta de delimitación conceptual y de distribución competencial», Revista de Administración pública, ${ }^{\circ} 177,2008$, pp. 195-228.

CASTEllà ANDREU, J. M., «La competencia en materia de consultas populares por la vía de referéndum en la STC 31/2010 sobre el Estatuto de Cataluña», Revista catalana de Dret public, número especial sentencia 31/2010 del Tribunal Constitucional sobre el Estatut d'autonomia de Catalunya, 2010, p. 308.

Corcuera AtienzA, J., «Soberanía y autonomía. Los límites al derecho a decidir (Comentario de la STC 103/2008)», Revista española de Derecho Constitucional, $\mathrm{n}^{\circ} 86,2009$, pp. 303-341.

CRUZ Villalón, P., «El referéndum consultivo como modelo de racionalización constitucional», Revista de Estudios políticos, $\mathrm{n}^{\circ} 13,1980$, pp. 145-168.

Garrorena Morales, Á., «Teoría y práctica española del referéndum», Anales de la Universidad de Murcia, Derecho, Vol. XXXI, no 3-4 ,1977, pp. 79-108.

GiCQUEL, J.É., «Faut-il introduire en France le référendum législatif d'initiative populaire?», Petites affiches, $\mathrm{n}^{\circ}$ 20, 2005, pp. 5-12.

Linde Paniagua, E., Herrero Lera, M., «El referéndum en la Constitución de 1978», Revista de Derecho Político, no 3, 1979, pp. 17-48.

— «Comentario a la Ley orgánica de modalidades de referéndum», Revista de Derecho Político, $\mathrm{n}^{\circ}$ 6, 1980, pp. 83-105.

LóPEZ BASAGUREN, A., «Sobre referéndum y Comunidades Autónomas. La ley vasca de la «consulta» ante el Tribunal Constitucional (consideraciones con motivo de 
la STC 103/2008)», Revista d'Estudis autonomics i federals, n 9, 2009, pp. 202238.

LÓPEZ GONZÁLEZ, J. L., El referéndum en el sistema español de participación politi$c a$, Universidad politécnica de Valencia, Valencia, 2005.

- «El referéndum nacional consultivo sobre decisiones políticas de especial trascendencia», Cuadernos de la Cátedra Fadrique Furió Ceriol, nº 38-39, 2002, pp. 207-218.

—El referéndum consultivo sobre decisiones políticas de especial trascendencia: reflexiones desde el principio democrático en relación al referéndum sobre la Constitución europea», Revista de Derecho Político, no 65, 2006, pp. 233-256.

LUCIANI, M., «El referéndum, cuestiones teóricas y de la experiencia italiana», Revista catalana de Dret public, $\mathrm{n}^{\circ} 37,2008$, pp. 157-182.

MARTín NúÑEZ, E., «Comentario a la Sentencia sobre el Estatuto. Competencia en materia de consultas populares (Art. 122 EC)», Revista catalana de Dret public, número especial sentencia 31/2010 del Tribunal Constitucional sobre el Estatut d'autonomia de Catalunya, 2010, pp. 316.

—El referéndum y las consultas populares en las Comunidades Autónomas y municipios», Revista vasca de Administración pública, nº 94, 2012, pp. 95-131.

Nuss, P., «Référendum et initiative populaire en France? De l'illusion en général et de l'hypocrisie en particulier», Revue du Droit Public, nº 5, 2000, pp. 1441-1493.

Oliver ArAujo, J., «El referéndum en el sistema constitucional español», Revista de Derecho Politico, n 29, 1989, pp. 115-184.

PÉrez Sola, N., La regulación constitucional del referéndum, Universidad de Jaén, Jaén, 1994.

Rosanvallon, P., Le mythe du citoyen passif, Le monde, 20 de junio de 2004.

SIEYES, E., Dire de l'abbé sur la question du veto royal à la séance du 7 septembre de 1789, Badouin, Paris, 1979.

URIARTE TORREALDAY, R., «Notas sobre la admisibilidad constitucional de consultas populares de ámbito autonómico», Revista vasca de Administración Pública, $\mathrm{n}^{\circ}$ 82, 2008, pp. 227-257.

TITLE: The consultative referendum in Spain: critical remarks and some proposals for the future

RESUMEN: La actual regulación del referéndum consultivo en el Art. 92 CE y en la Ley orgánica que lo desarrolla presenta algunas carencias merecedoras de reflexión. Más allá de la mejora de concretas cuestiones procedimentales, en términos de calidad democrática parece conveniente su potenciación, incorporando junto a estas consultas sobre decisiones politicas de especial trascendencia referéndums estatales de tipo legislativo y una referencia a otras consultas de ámbito autonómico y local y permitiendo a la ciudadanía poner en marcha estos instrumentos de participación directa. Varias proposiciones en tramitación siguen este camino, sin perjuicio de que, como aquí se intentará, se pueda aportar alguna sugerencia más al debate.

PALABRAS CLAVE: participación. Referéndum. España 
ABSTRACT: The current referendum regulation in Article $92 \mathrm{SC}$ and the organic law that develops it have some shortcomings worthy of reflection. Beyond improving specific procedural issues, in terms of democratic quality it seems appropriate to empower it, by incorporating beside these consultations of particularly important political decisions, legislative state referendums and a reference to other local or regional referendums, allowing the citizenship to implement these instruments of direct participation. Several proposals in the pipeline follow this path, in spite of the possibility of making any suggestions to the debate, as here we will try to do.

KEYWORDS: Participation. Referendum. Spain

RECIBIDO: 14.10 .2013

ACEPTADO: 26.05.2014 